\title{
Aykırı değerler içeren VLF verilerinin süzgeçlenmesinde budanmış ortalama, Empirik Mod Ayrışımı ve dayanıklı regresyon yöntemlerinin karşılaştırılması
}

\section{Comparison of trimmed mean, Empiric Mode Decomposition and robust regression methods for filtering VLF data with outliers}

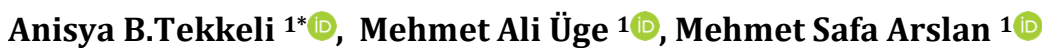 \\ 1 İstanbul Üniversitesi - Cerrahpaşa, Mühendislik Fakültesi, Jeofizik Mühendisliği Bölümü, Büyükçekmece, İstanbul, \\ TÜRKIYE \\ Sorumlu Yazar / Corresponding Author*: anisya@iuc.edu.tr \\ Gelis Tarihi / Received: 12.05.2021 Araștırma Makalesi/Research Article \\ Kabul Tarihi / Accepted: 05.09.2021 DOI:10.21205/deufmd.2022247002 \\ Atıfssekli/How to cite: : B.TEKKELI, A., ÜGE, M.A., ARSLAN, M.S.(2022).Aykırı değerler içeren VLF verilerinin süzgeçlenmesinde budanmıs \\ ortalama, Empirik Mod Ayrışımı ve dayanıklı regresyon yöntemlerinin karşılaştırılması. DEUFMD, 24(70), 7-18.
}

Öz

Çok Düșük Frekans (VLF) elektromanyetik yöntem , yeraltının sığ iletkenlik dağılımının belirlenmesi için sıklıkla uygulanır. Toplanan VLF verileri genelde aperiyodiktir ve bu nedenle doğrusal olmayan süzgeçleme yöntemleri VLF verilerinin gürültüden arındırılması için sıklıkla uygulanmaktadır. Bu çalışmada, aykırı değerler içeren verilerin değerlendirilmesinde daha başarılı yöntemlerin belirlenmesi için farklı doğrusal olmayan süzgeçler kuramsal ve gürültülü arazi verilerine uygulanmıștır. Kuramsal verilerin aksine, arazi verilerinde gerçek yeraltı modeli bilinemediği için, aynı ölçüm hattı üzerinde farklı zamanda toplanmış VLF-R ve Elektrik Rezistivie Tomografisi verileri değerlendirilmiștir ve sonuçları yeraltının daha doğru bir temsili olarak kabul edilmiștir. Kuramsal ve arazi verileri üzerinde gerçekleştirilen uygulamalarda, aykırı değerler içeren verilerde dayanıklı regresyonun diğer yöntemlere göre daha başarılı olduğunu göstermiştir.

Anahtar Kelimeler: VLF, Empirik Mod Ayrışımı, dayanıklı regresyon, budanmış ortalama, ters çözüm

\begin{abstract}
Very Low Frequency (VLF) electromagnetic method is widely implemented to determine shallow conductivity distribution of subsurface. Collected VLF data are usually aperiodic and consequently non-linear filtering techniques are often used for eliminating noise in VLF data. In this study, several non-linear filtering methods are implemented on synthetic and field data to determine methods performing better in case of outliers in data. In contrary of synthetic studies, the true subsurface model is unknown for the field data. Hence, VLF-R and Electrical Resistivity Tomography data, which are also collected over the same measuring profile, are also interpreted and their results are assumed as better representations of the subsurface. Applications on noisy synthetic and field datasets showed that the robust regression performs better than the other techniques in case of data with outliers.
\end{abstract}

Keywords: VLF, Empiric Mode Decomposition, robust regression, trimmed mean, inversion 


\section{Giriş}

VLF yöntemi, 15-30 kHz bandında yayın yapan vericilerin sinyallerinin yer içerisinde olușturduğu yanıtın ölçüldüğü ve sığ derinliklerdeki $(<100 \mathrm{~m})$ iletkenlik dağılımının belirlenmesi amacıyla uygulanan bir jeofizik yöntemdir. Diğer uzak alan, frekans ortamı elektromanyetik yöntemler gibi VLF yöntemi de iletkenlere karşı daha duyarlıdır. VLF yöntemi, sığ maden yatakları ve taş ocakları üzerinde [12], yeraltı suyu [3-4] ve fay araștırmalarında [58], arkeojeofizik çalışmalarda [9-10] ve kirlilik araştırmalarında [11-13] uygulanmaktadır.

VLF yöntemi, ölçülen bileşenlere bağlı olarak iki isimle anılır; sadece manyetik alanın yatay ve düșey oranlarından elde edilen tipper verilerinin incelendiği VLF-EM ve ilaveten elektrik alan ölçümlerinden elde edilen Cagniard görünür özdirenci [14] ve faz verilerinin de incelendiği VLF-R yöntemidir. Veriler, ölçülen elektrik ve manyetik alan bileșenlerinin farklı oranlarından aşağıdaki biçimde elde edilirler.

$$
\begin{aligned}
& T_{z y}=\frac{H z}{H y} \\
& \rho_{\alpha}=\frac{1}{\omega \mu_{0}}\left|\frac{E_{X}}{H_{Y}}\right|^{2} \\
& \Phi=\tan ^{-1}\left[\frac{\operatorname{Im}\left(E_{X} / H_{Y}\right)}{\operatorname{Re}\left(E_{X} / H_{Y}\right)}\right]
\end{aligned}
$$

Yukarıda verilen bağıntılarda, $H_{z}$ ve $H_{y}$ ölçülen manyetik alanın düșey ve yatay bileșenleridir; $E_{X}$ ise yatay manyetik alana dik yatay yöndeki elektrik alan bileșenidir. Açısal frekans $\omega$ ile gösterilmiştir; boşluğun manyetik geçirgenliği $\mu_{0}$ ile gösterilmiștir ve değeri $4 \pi 10^{-7} \mathrm{H} / \mathrm{m}^{\prime}$ dir. VLF yönteminde, eşitlik (1)'de verilen tipper verileri genellikle yüzde oran olarak incelenir.

VLF verilerindeki temel gürültü kaynakları, küresel fırtına ve yıldırım aktivitesi ile örtüşen mevsimsel gürültüler [15-16], depremlerden kaynaklı sinyaller [17], elektrik hatlarından kaynaklı gürültüler [18], yeraltındaki heterojeniteden kaynaklı jeolojik gürültü [19] ve arazideki yüksek frekanslı engebeden kaynaklı gürültüdür [20].

VLF ölçümlerinde yüksek gürültü ve bazı noktalarda aykırı değerler (outlier) gözlenebilmektedir. $\mathrm{Bu}$ etkilerin giderilmesinde sıklıkla alçak geçişli süzgeçler uygulanmaktadır.
Fourier analizi ile frekans ortamında süzgeçleme, verilerin periyodik veya durağan değişim gösterdiğini ve lineer olduğunu varsayar [21]. Bu nedenle VLF gibi uzanımsal ölçümlerde gürültünün giderilmesi için doğrusal olmayan süzgeçler çoğu zaman Fourier spektrumlarının hesaplanmasına tercih edilmektedir [21-22]. Bu çalışmada, aykırı değerlere karşı etkili olan bazı süzgeçleme yöntemleri incelenmiștir. Bu amaçla, kayan budanmış ortalama (rolling trimmed mean), dayanıklı regresyon (robust regression) ve Empirik Mod Ayrıșımı (Empirical Mode Decomposition, EMD) yöntemleri kuramsal ve arazi verilerine uygulanmıştır.

$\mathrm{Bu}$ süzgeçlerden, kayan budanmış ortalama, verilerin pencerelenen bir kısmının ortalama değerinin hesaplanarak pencerenin orta noktasına atanmasıyla uygulanır. Pencere veri boyunca kaydırılarak süzgeçlenmiș veri elde edilir. Budama işlemi, pencerelenen veri parçasının en büyük ve en küçük elemanlarının ortalama dıșı bırakılmasını sağlar, böylece aykırı değerler işlemden atılır. Yöntem bu şekliyle, kayan medyan (moving median) yöntemine yakınsamaktadır. Dayanıklı regresyon (robust regression), verilerin aykırı değerler içermesi durumunda en küçük kareler yöntemine göre daha bașarılıdır [23] ve sıklıkla tercih edilmektedir. EMD [21], verilerin görsel değerlendirilmesini de içeren bir süzgeçleme yöntemidir ve VLF verilerinin süzgeçlenmesi için [24-25] tarafından kullanılmıștır. Daha sonra, [26-29] çalışmalarında da aynı amaçla uygulanmıştır ve başarılı olduğu gösterilmiştir.

$\mathrm{Bu}$ çalışmada uygulanan süzgeçlerin gürültülü verilere etkilerini göstermek amacıyla, süzgeçlenmiş verilerden yuvarlatıcılı ters çözüm ișleci ile iki boyutlu özdirenç modelleri elde edilmiş ve birbirleriyle kıyaslanmıștır. Yuvarlatıcılı ters çözüm (smooth inversion) işleçleri VLF ve diğer elektromanyetik indüksiyon verilerinden yer iletkenlik modellerinin elde edilmesi için sıklıkla kullanılmaktadır. Çeşitli örnekler [1,27, 29-32]' de bulunabilir.

\section{Materyal ve Metot}

\subsection{Kayan Budanmış Ortalama}

Kayan budanmış ortalama, hat boyunca ölçülen verilerden ardişık bir grup verinin (alt veri grubu) ortalamasının alınıp orta noktaya atanmasıyla gerçekleștirilir. Budama işlemi, ortalaması alınacak alt veri grubundan istenen 
oranda en büyük ve en küçük değerlerin atılmasını sağlamaktadır. Budama oranı arttıkça, orta noktaya atanacak değer de medyana yakınsayacaktır. Süzgeç, veri noktaları boyunca kaydırılarak bütün ölçüm noktalarına uygulanır.

Buna göre VLF hattı boyunca bir frekansta toplanan bir veriye ait yöney aşağıdaki gibi verilebilir.

$$
d_{v}=d_{v, 1}, \quad d_{v, 2}, \ldots, \quad d_{v, \text { nobs }}
$$

Eşitlik (4)'de, nobs istasyon (ölçüm noktası) sayısıdır, v toplanan verinin türüdür (VLF-R için görünür özdirenç, faz ve tipper). Bu veri grubu için kayan budanmış ortalama için sözde kod (pseudocode) aşağıdaki gibi verilebilir.

Tablo 1. Kayan budanmış ortalama için sözde kod

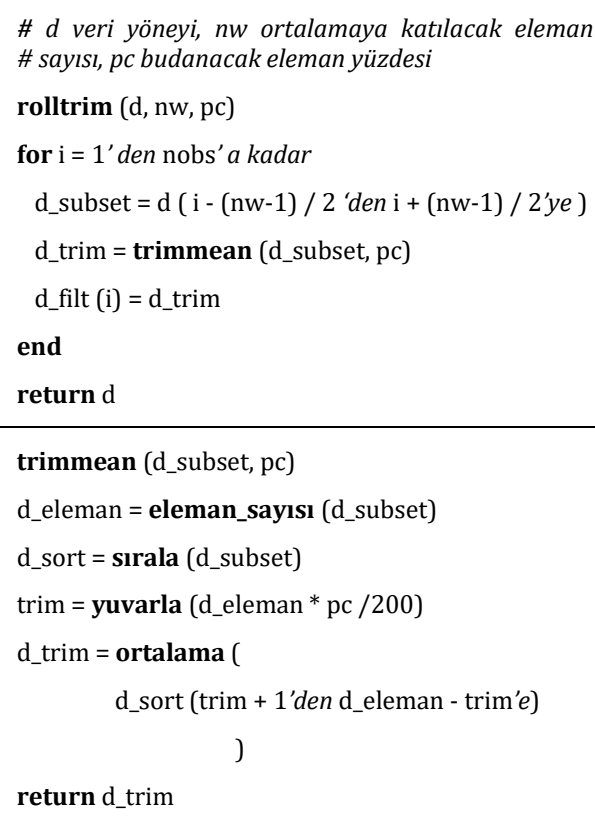

\subsection{Empirik Mod Ayrışımı (EMD)}

EMD yöntemi [21], verilerdeki gürültünün tamamen rastgele olduğunu varsayan bir yöntemdir. Buna göre, verilerde trend üzerine eklenmiş pozitif ve negatif yönlü salınımlar birbirine eşit sayıdadır, ayrıca pozitif ve negatif genlikleri çevreleyen zarfın ortalama değeri sıfırdır. Tarif edilen, VLF verilerindeki gürültü kaynaklı salınımlara karşılık gelen bu bileşen "Intrinsic Mode Function" (IMF) olarak anılmaktadır. Bu tanıma göre veri, trend ve farklı
IMF'lerin toplamından oluşmaktadır. Bu salınım bileșenlerinin belirlenip veriden ayrilabilmesi için [21] elekten geçirme (sifting) adı verilen bir işlem önerilmiştir. $\mathrm{Bu}$ işlem, verideki salınımların yerel maksimum ve minimumlarının elle seçilmesini içermektedir. Bunları saran zarf, seçilen maksimum ve minimum noktalardan geçen birer kübik eğri (cubic spline) tanımlanarak olușturulmaktadır. Elekten geçirme işlemi, salınımları saran zarf sıfır eksenine göre yaklaşık simetrik olana kadar devam ettirilir. İstenen koşul sağlandıktan sonra elde edilen salınım modu 1. IMF olarak adlandırılır ve verilerden çıkarılır. IMF'ler veri sadece trendi içerir hale gelene kadar belirlenip verilerden atılabilir.

Aşağıda, örnek yüzde gerçel bileşen tipper verisi (\% in-phase) için IMF’lerin ayrıştırılarak trendin elde edilmesine bir örnek verilmiştir. İlgili işlem, [27] çalışmasında kullanılan kod ile gerçekleştirilmiştir. Şekil 1a'da veri gösterilmiştir. Veriden yerel maksimum ve minimumların seçilmesiyle elde edilen 1. IMF Şekil 1b'de verilmiștir. Ancak bu aşamada, IMF'yi çevreleyen zarfın ortalamaları sıfır olmadığı için gerekli koşulları sağlamamaktadır. [21] tarafından tanımlanan "sifting" işlemi tekrar edildiğinde zarf sıfir ekseninde simetrikleşmektedir (Şekil 1c). Zarf yaklaşık simetrik olduğunda 1 . IMF elde edilmiş olur (Şekil 1d). 2. IMF, 1. IMF'nin veriden atılmasıyla elde edilen rezidüelden aynı işlemlerle hesaplanır (Şekil 1e). Bu şekilde, elde edilen IMF' ler veriden atılarak doğrusal trende ulaşılır (Şekil 1f).

\subsection{Dayanıklı Regresyon}

Dayanıklı regresyon yöntemleri verilerdeki aykırı değerlerden, en küçük kareler yöntemine göre daha az etkilenir ve bu nedenle sıklıkla uygulanır [23, 33]. Bu metotlar, avantajlarına rağmen birçok yazılım kütüphanesinde tanımlı değildir [34] ve belki de bu nedenden ötürü görece az uygulanmaktadır.

Eğri çakıștırma ve eğri çakıştırma ile gürültünün atılması işlemlerinde genellikle en küçük kareler (L2 norm) yöntemi kullanılır. En küçük kareler ile minimize edilmek istenen fonksiyon aşağıdaki gibi verilmektedir.

$$
U=\sum_{i=1}^{n}\left(d_{i}-x_{i}\right)^{2}
$$


L2 norm yöntemler tek bir aykırı değerden bile olumsuz etkilenebilmektedir, dayanıklı metotlar bu probleme çözüm bulmayı amaçlar. Tanımlanabilecek en basit dayanıklı regresyon, en küçük mutlak değerler normunu (L1 norm) minimize etmeyi amaçlar.

$$
U=\sum_{i=1}^{n}\left|d_{i}-x_{i}\right|
$$

Yukarıda verilen eşitliğin (6) en büyük problemi, her noktada türevinin olmamasıdır. Bu durum programlamada güçlük yaratmaktadır. Bunu aşmak için genelde en küçük kareler yöntemi değiștirilerek dayanıklı regresyona denk hale getirilmektedir [33]. Bu çalışmada kullanılan algoritmada, eșitlik (5)' de verilen en küçük kareler rezidüel ifadesi yerine "soft L1 loss" fonksiyonu kullanılmıştır. $\mathrm{Bu}$ fonksiyon $\mathrm{L} 2$
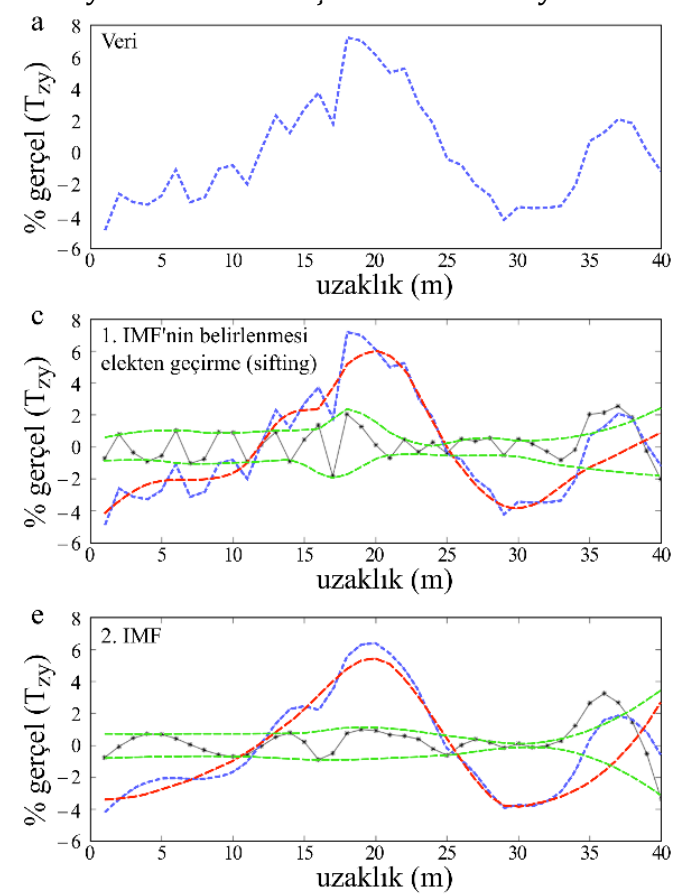

(eşitlik 5) ve L1 (eşitlik 6) normlarının özelliklerini birleştirir.

$$
\mathrm{z}=(d-x)^{2}
$$

olmak üzere, soft L1 loss aşağıdaki gibi verilebilir.

$$
L 1_{\text {soft }}=2(\sqrt{1+z}-1)
$$

Buna göre değiştirilmiş en küçük kareler yöntemi, her nokta için eșitlik (8) ile elde edilen rezidüel değerlerin toplamını minimize etmeye çalışır. Bu çalıșmada, dayanıklı regresyon hesapları için SciPy numerik hesaplama kütüphanesi [35] kullanılmıștır.
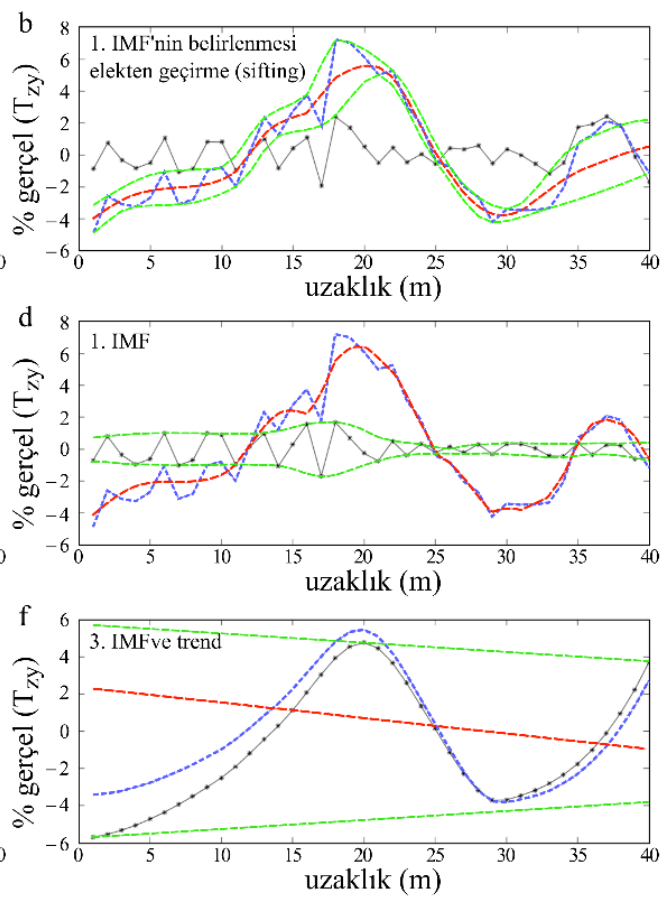

Sekil 1. Örnek \% gerçel tipper anomalisi için IMF’lerin elde edilmesi. a) Veri (mavi) b) Maksimum ve minimumların ilk defa seçilmesinden sonra 1. IMF siyah çizgiyle gösterilmiştir (bu aşamada IMF'nin yerel ortalamaları 0 olmadığı için aranan koșulları sağlamamaktadır). c) Elekten geçirme işlemi 2. defa gerçekleştirildikten sonra zarf (yeşil) simetrikleşmeye başlamıştır. d) 1. IMF ve rezidüel (kırmızı). e) Elde edilen 2. IMF. f) 3. IMF ve doğrusal trend (rezidüel). Şekillerde, veri mavi renkle, veri ile IMF'nin farkından elde edilen rezidüel kırmızı renkle; seçilen maksimum ve minimumları saran zarf yeşil ile gösterilmiștir.

\subsection{Yuvarlatıcılı Ters Çözüm}

VLF ve diğer elektromanyetik indüksiyon yöntemlerinde, verilerden yeraltı özdirenç dağılımına ulaşmak için çoğunlukla Tikhonov düzgünleyicisi ile doğrusal olmayan en küçük kareler ters çözümü kullanılır. Literatürde birçok düzgünleyici fonksiyon tanımlanmıştır. 
$\mathrm{Bu}$ fonksiyonların elde edilen modellere etkilerine dair bir derleme [30]'de bulunabilir. Düzgünleyici fonksiyonların en çok kullanılanı yuvarlatıcı fonksiyondur [36, 37]. Yuvarlatıcılı ters çözüm (smooth inversion) ölçülen verileri sağlayan en düşük kabalıklı yapı sınırlarına sahip modelin elde edilmesini amaçlar. İlgili düzgünleyici, ters çözüm içerisine, basit sonlu farklar türev dizeyleri ile eklenir ve yuvarlatıcı dizey (smoothing matrix) olarak adlandırılır.

Yuvarlatıcılı ters çözüm, ilk yinelemede $(i=0)$ başlangıç modelinden $\left(\mathbf{m}_{0}\right)$ başlayarak model parametrelerini aşağıdaki denklemle elde eder.

$$
\begin{aligned}
& \mathbf{m}_{i+1}=\left[\mu \mathbf{C}^{T} \mathbf{C}+\right. \\
& \left.(\mathbf{W} \mathbf{J})^{T} \mathbf{W} \mathbf{J}\right]^{-1}(\mathbf{W} \mathbf{J})^{T} \mathbf{W}\left(\mathbf{d}-\mathbf{F}\left[\mathbf{m}_{i}\right]+\right. \\
& \left.\mathbf{J m}_{i}\right)
\end{aligned}
$$

Denklemde, m model parametre yöneyi, C yuvarlatıcı dizey, $\mu$ model kabalığı ile hesaplanan ve gözlenen veriler arasındaki çakıșmayı dengeleyen Lagrange çarpanı, $\mathbf{W}$ ağırlık dizeyi, J hesaplanan verilerin model parametrelerine göre kısmi türevlerinden olușan Jacobian dizeyi, d gözlenen veri yöneyi, $\mathrm{F}\left[\mathrm{m}_{\mathrm{i}}\right]$ mevcut model parametreleri $\mathbf{m}_{i}$ ile hesaplanan verilerin (düz çözüm) yöneyidir.

Ters çözüm sonuçları incelenirken, çakışma ölçütü olarak karekök ortalama (RMS) hata kullanılmıștır. Karekök ortalama hata aşağıdaki gibi tanımlanmaktadır.

$$
R M S_{\text {hata }}=\sqrt{\frac{W(\mathbf{d}-\mathbf{F}[m])^{T}(\mathbf{d}-\mathbf{F}[m])}{n d}}
$$

Denklemde, $n d$, gözlenen veri yöneyinin boyudur (veri adedi).

Bu çalıșmada yuvarlatıcılı ters çözüm için [27]' de kullanılan, MATLAB ortamında geliștirilmiş ters çözüm işleci kullanılmıştır. İșleç, düz çözüm için sonlu elemanlar yöntemini kullanmaktadır. Ters çözümde Lagrange çarpanını elde etmek içinse Occam yaklaşımı kullanılmıştır [36, 37].

\section{Bulgular}

\subsection{Kuramsal Çalışmalar}

Budanmış ortalama, dayanıklı regresyon ve EMD yöntemleri ilk olarak kuramsal veriler üzerinde sınanmıștır. Kuramsal veri kümesinin elde edilmesi için, $50 \Omega \mathrm{m}$ özdirençli ortam içerisinde farklı dalıma sahip iki adet iletken $(10 \Omega \mathrm{m})$ tanımlanmıştır (Şekil 2a). Veriler, TE modu için tek frekansta $(23,4 \mathrm{kHz})$ hesaplanmıstır. Arazi verisini daha iyi temsil etmesi için hesaplanan verilere \%5 Gauss gürültüsü eklenmiştir (Şekil 3, düz çizgi). Bu veriler yuvarlatıcılı ters çözüm ile modellenmiștir (Şekil 2b) ve verilerin tanımlanan iletkenlerin belirlenmesi için yeterli bilgi taşıdığı gösterilmiștir. Daha sonra, verilere aykırı değerler de ilave edilerek ters çözümün nasıl etkilendiği gösterilmiștir (Şekil $4 a$, Şekil $5 a)$. İlgili şekillerde de görüleceği üzere, aykırı değerler, modelin solundaki iletkenin doğru bir şekilde elde edilmesini engellemektedir.

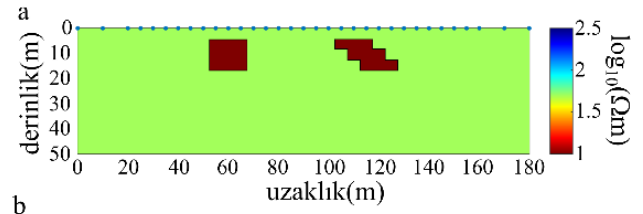

$\mathrm{b}$

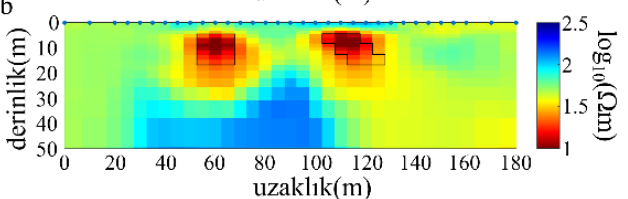

Şekil 2. a) Kuramsal verilerin elde edilmesi için tanımlanan model. b) Verilere \%5 Gauss gürültüsü eklendikten sonra yuvarlatıcılı ters çözümle elde edilen model (10 yineleme, 1 RMS).

Verilerin düzeltilmesi için öncelikle kayan budanmıș ortalama yöntemi ardıșı 7 nokta ve \%50 budama ile uygulanmıştır (Şekil 4b, Șekil 5b). Budanmış ortalama, aykırı değerleri yok etse de soldaki iletkenin anomalisini yeterli seviyede temizleyememiştir. Bunun sonucu olarak ilgili iletken belirlenememiștir. Dayanıklı regresyonun ise aykırı değerleri bașarılı bir şekilde temizlediği ve her iki iletkenin de belirlenebildiği gözlenmektedir. Buna karșın başta sağdaki iletken olmak üzere, her iki yapının da yatay yöndeki konumları kaymıș biçimde elde edilmiştir (Şekil 4c, Şekil 5c). EMD yöntemi, salınımların yerel ortalamalarının veriye eșit olduğunu varsaymaktadır. Hazırlanan kuramsal veri kümesindeki aykırı değerler bu ilişkiyi bozmaktadır. EMD yöntemi kısmen gözle verilerin muayenesini içerdiğinden, aykırı değer olduğu kolay anlaşılan noktaların IMF zarflarının dıșında bırakılmasına gayret edilmiștir. EMD ile elde edilen bulgulara (Şekil 4d, Şekil 5d) göre soldaki iletken kısmen belirlenebilmektedir ancak aykırı değerlerin etkileri hala gözlenmektedir. Budanmış ortalama ve EMD yöntemlerinin, dayanıklı regresyon kadar başarılı olamadığı gözlenmiştir. 


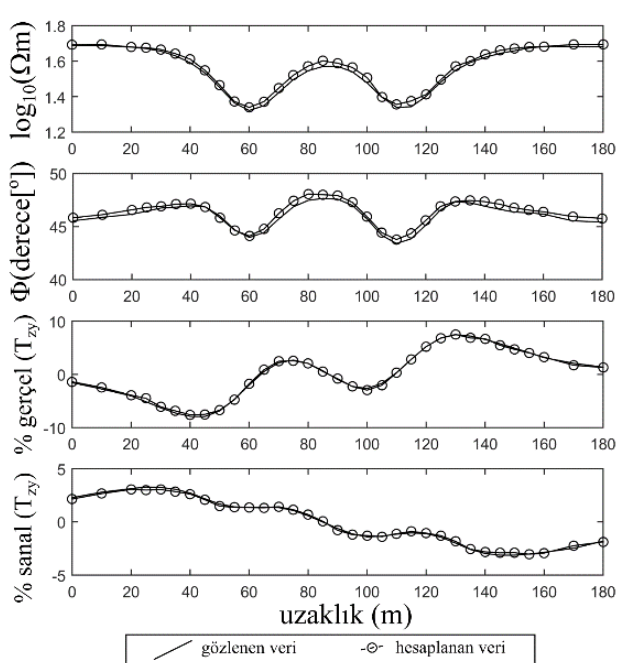

Şekil 3. \%5 Gauss gürültülü görünür özdirenç, faz ve tipper verilerin, yuvarlatıcılı ters çözüm sonucu (10 yineleme, 1 RMS) için gözlenen ve hesaplan veriler.

\subsection{Saha Çalışması}

Arazi verisi olarak Kocaeli, Başiskele İlçesi Kullar Köyü'nde Kuzey Anadolu Fayı'nın (KAF) konumu bilinen yüzey kırığı üzerinde (Şekil 6) Scintrex Eda Omnit VLF-R cihazı ile toplanmış ölçümler kullanılmıştır. Araştırma bölgesinde, yüzey Kuvaterner alüvyon ile kaplı olup [38], kalınlığı 100 m'den büyüktür [39].

Ölçümler ilgili hat üzerinde TE modunda, $23,4 \mathrm{kHz}$ frekansinda (DHO38-Almanya) ve $5 \mathrm{~m}$ elektrot açıklığıyla gerçekleştirilmiştir. Ölçüm hatları, fay uzanımına ve istasyon konumuna uygun biçimde Güney-Kuzey uzanımlıdır. Birinci gün 3m (hat-1), ikinci gün $2 \mathrm{~m}$ (hat-2) olacak şekilde farklı istasyon aralıklarıyla ardışık iki gün ölçü toplanmıştır. İkinci gün toplanan tekrarlama ölçümlerinde (hat-2), bilinmeyen bir nedenden ötürü görünür özdirenç ve faz verilerinde yüksek miktarda gürültü ve çok sayıda aykırı değer gözlenmiştir; tipper verileri ise gürültüden etkilenmemiştir. Bu nedenle, gözlenen gürültü, VLF sinyallerinde zamana bağlı gürültüye neden olan kaynaklarla [15-18] ve arazi koşullarına bağlı gürültülerle [19-20] ilişkilendirilememiştir. Gürültü kaynağı sadece elektrik alanda bozulmaya yol açmıştır, bu nedenle kültürel (topraklama vb.) olarak yorumlanmıştır.
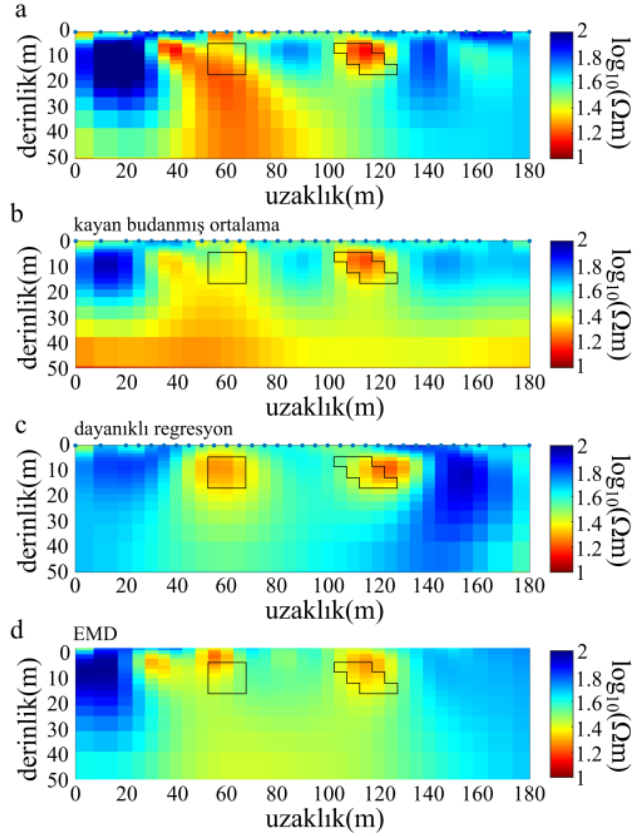

Şekil 4. a) \%5 Gauss gürültülü verilere aykırı değerlerin eklenmesinden sonra yuvarlatıclı ters çözümle elde edilen model (7 yineleme, 1 RMS). b) Kayan budanmış ortalama ile süzgeçlemeden sonra ters çözüm sonucu (8 yineleme, 1 RMS). c) Dayanıklı regresyonla temizlenen verilerin ters çözüm sonucu (17 yineleme, 1 RMS). d) EMD yöntemi uygulaması sonrasında ters çözümle elde edilen model (17 yineleme, 1RMS).

Yeraltının iyi bir temsilini sağlayacağı öngörülen, hat-1 üzerindeki VLF-R verilerinin iki boyutlu ters çözüm sonucu (9 yineleme, 1,23 RMS) Şekil 7a' da ve aynı hatta 48 kanallı METZ SAS 24 SD model cihazla Wenner-Schlumberger dizilimiyle $2 \mathrm{~m}$ elektrot aralığıyla toplanmış Elektrik Rezistivite Tomografisi (ERT) verilerinin ters çözümü sonucu (6 yineleme, 2,51 RMS) Şekil 7b' de verilmiştir. ERT verilerinin ters çözümü [40] çalışmasında verilen işleç ile gerçekleştirilmiştir. Toplanan VLF$R$ verilerinden sadece görünür özdirenç ve faz verilerinin ters çözümüyle elde edilen model (5 yineleme, 1 RMS) Şekil 7c' de verilmiştir. Bu üç modele ait gözlenen ve hesaplanan veriler Şekil 8 'de sunulmuştur. Bu modellere göre yatay eksende $\sim 35 \mathrm{~m}^{\prime}$ de bulunan fay yeraltında önemli bir özdirenç karşıtlığına neden olmaktadır. Modellerde, fayın bir yanı oldukça iletken, diğer yanı ise yüksek özdirençlidir.

Tekrar ölçülerinde toplanan görünür özdirenç ve faz verilerinde (hat-2) çok sayıda aykırı değer 
bulunmaktadır. Lineer olmayan süzgeçlerin gürültülü veriler üzerinde sağlıklı bir şekilde karş1laştırılabilmesi için sadece gürültülü olan görünür özdirenç ve faz verileri modellenmiştir; gürültü seviyesi düşük olan tipper verileri ise modellemeyi yönlendirmemesi için ihmal edilmiştir. Sügeçlenmemiş veriler modellenirken görünür özdirenç verilerinde hata taban1 $\% 10$ kabul edilmiștir (faz için yarısı kabul edilmiștir). 7 yineleme sonucunda elde edilen 2,6 RMS hataya sahip Şekil 9a'da verilen modelin Şekil 7a ve 7c'de verilen VLF-R modellerinden ve Şekil 7b'de verilen ERT modelinden uzak olduğu gözlenmektedir.
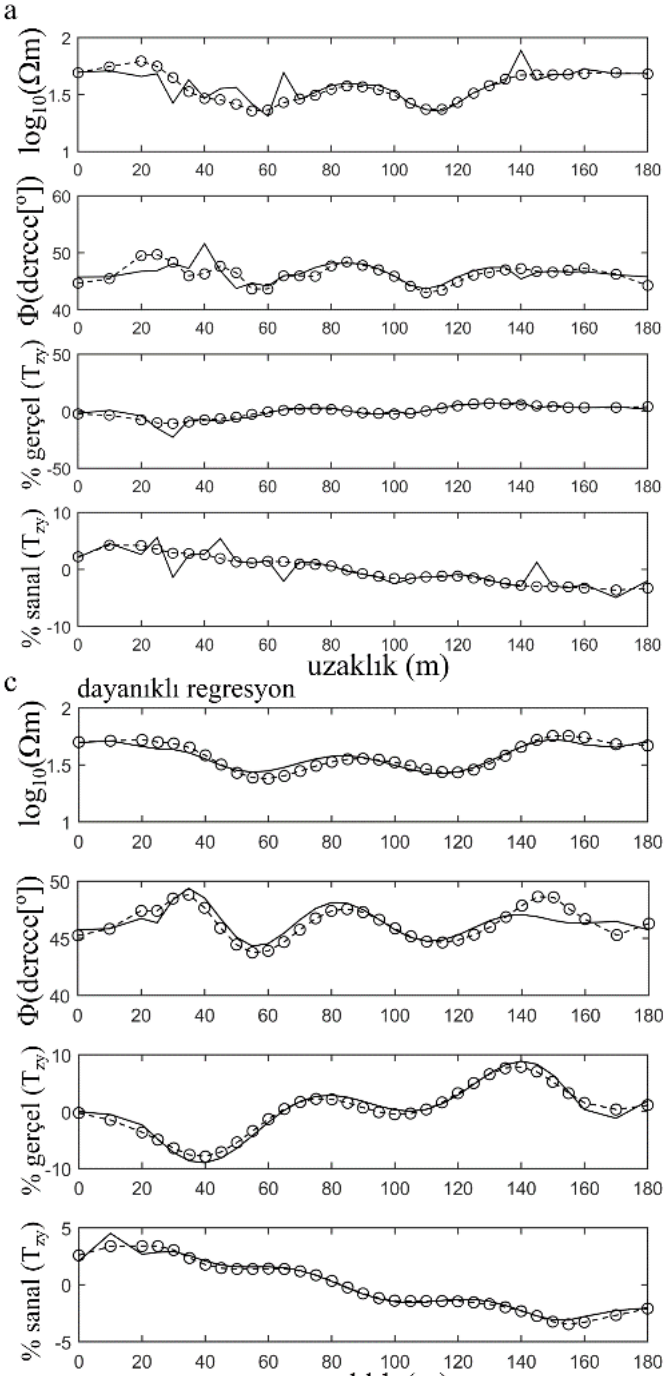

uzaklık (m) b kayan budanmış ortalama
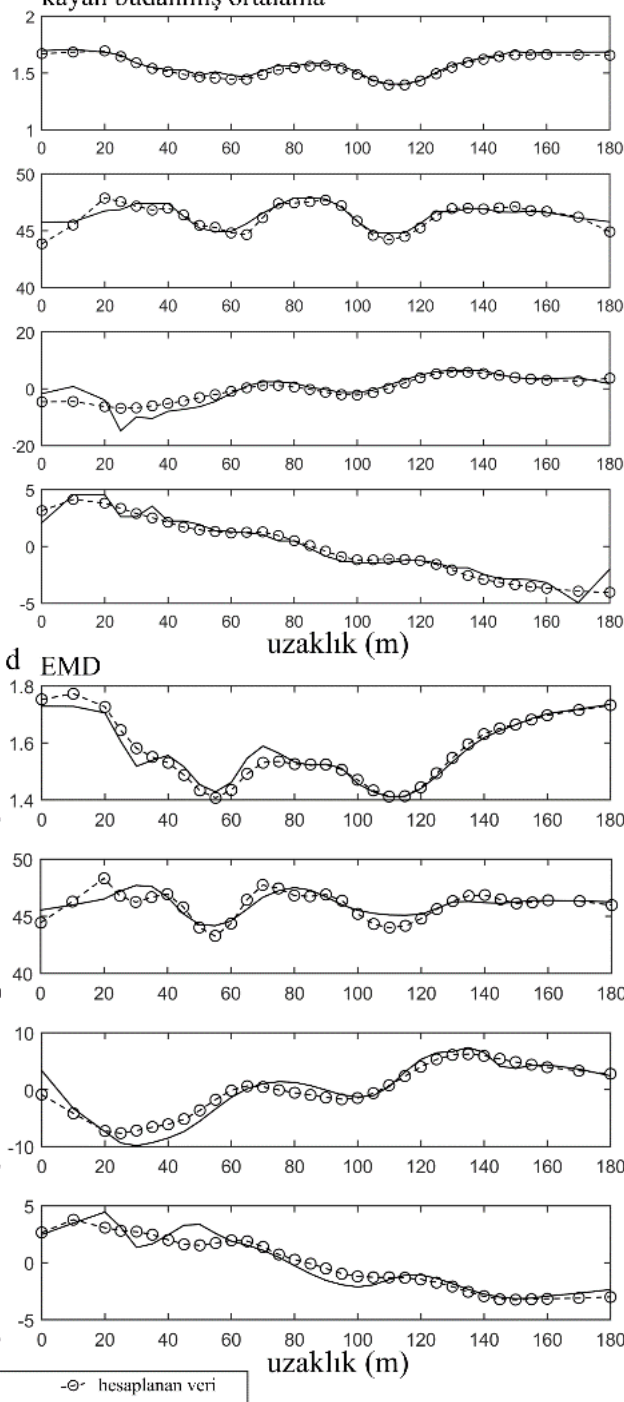

Şekil 5. \%5 gürültülü ve aykırı değerler eklenmiş veriler için yuvarlatıcılı ters çözüm sonucu (a)’ da verilmiştir (7 yineleme, 1 RMS). Budanmış ortalama (8 yineleme, 1 RMS), dayanıklı regresyon (17 yineleme, 1 RMS), EMD uygulanmalarından (17 yineleme, 1 RMS) sonra gözlenen veriler ve yuvarlatıcılı ters çözümle elde edilen modelere ait hesaplanan veriler sırasıyla (b), (c) ve (d)' de verilmiştir. 


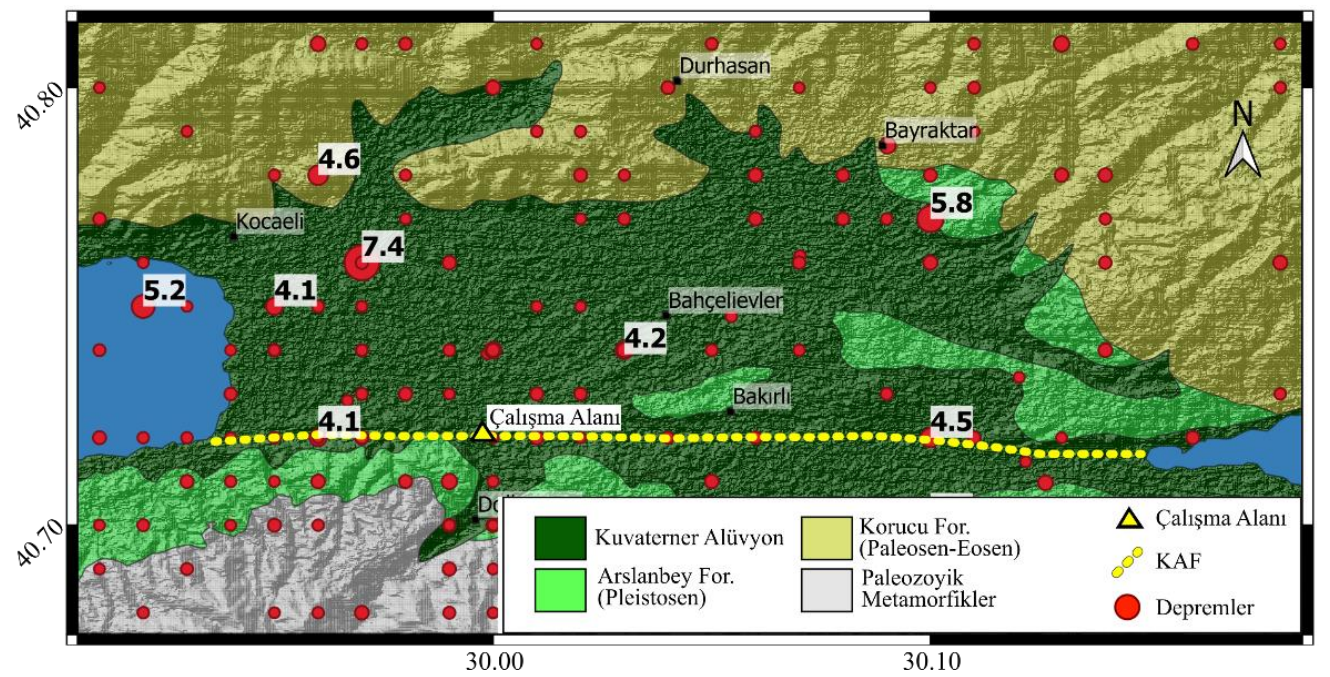

Şekil 6. Çalışma alanının basitleştirilmiş jeolojisi ([38]' den değiştirilerek çizilmiştir). Deprem verileri 1907-2020 yılları arasını kapsamakta olup Kandilli Rasathanesi ve Deprem Araştırma Enstitüsü veri tabanından alınmıştır.

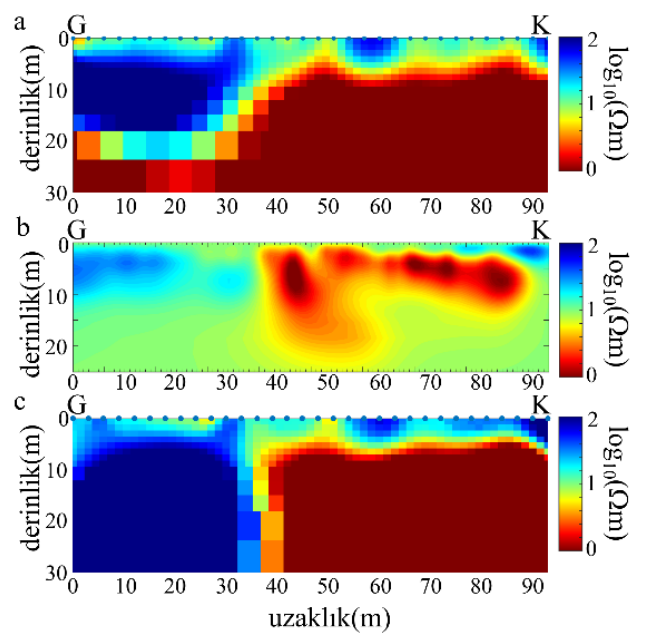

Şekil 7. a) Kocaeli'de, KAF' nın yüzey kırığı üzerinde hat-1 üzerinde toplanmıș, VLF-R verileri ile elde edilen model (9 yineleme 1,23 RMS), b) Aynı hat üzerinde toplanmış ERT verilerinin ters çözüm sonucu (6 yineleme 2,51 RMS). c) Sadece VLF-R görünür özdirenç ve faz verilerinin ters çözümüyle elde edilen model (5 yineleme, 1 RMS).
$\mathrm{Bu}$ bilgiler ıșığında, budanmıs ortalama, dayanıklı regresyon ve EMD yöntemleri hat-2 üzerinde toplanan gürültülü VLF-R verilerine uygulanmıștır ve Şekil 7 ile karşılaştırılarak yorumlanmiştır.

Kayan budanmış ortalama ve dayanıklı regresyon ve EMD için veriler değerlendirilirken görünür özdirenç ve tipper için hata tabanı \%5, faz için \%2,5 kabul edilmiştir.

Hat-2 için, kayan budanmıs ortalama (5 yineleme, 1 RMS) ve EMD süzgeci ile elde edilen (4 yineleme, 1RMS) modeller birbirine oldukça benzerdir (Şekil 9 b, d) ancak fayın konumu yatayda $\sim 45 \mathrm{~m}^{\prime}$ de elde edilmiștir. EMD uygulanırken, kuramsal verilerde olduğu gibi, aykırı değerler yorumlanarak süzgecin etkilenmemesi için çalışılmıştır (Şekil 10). Faz verileri için elde edilen 2. IMF'de (Șekil 10, en alt) zarf dışında kalan değerler görülebilir. $\mathrm{Bu}$ değerlerin zarfın dışında kalmasının sebebi, yakınlarında aksi yönde eșit genlikli aykırı değer bulunmamasıdır. Bu aykırı değerler EMD'nun temel varsayımlarına uymayan bir şekilde; kullanıcı yorumuyla zarf dışında bırakılarak veriden atılmıştır, buna karşın yöntem başarılı olamamıștır. 

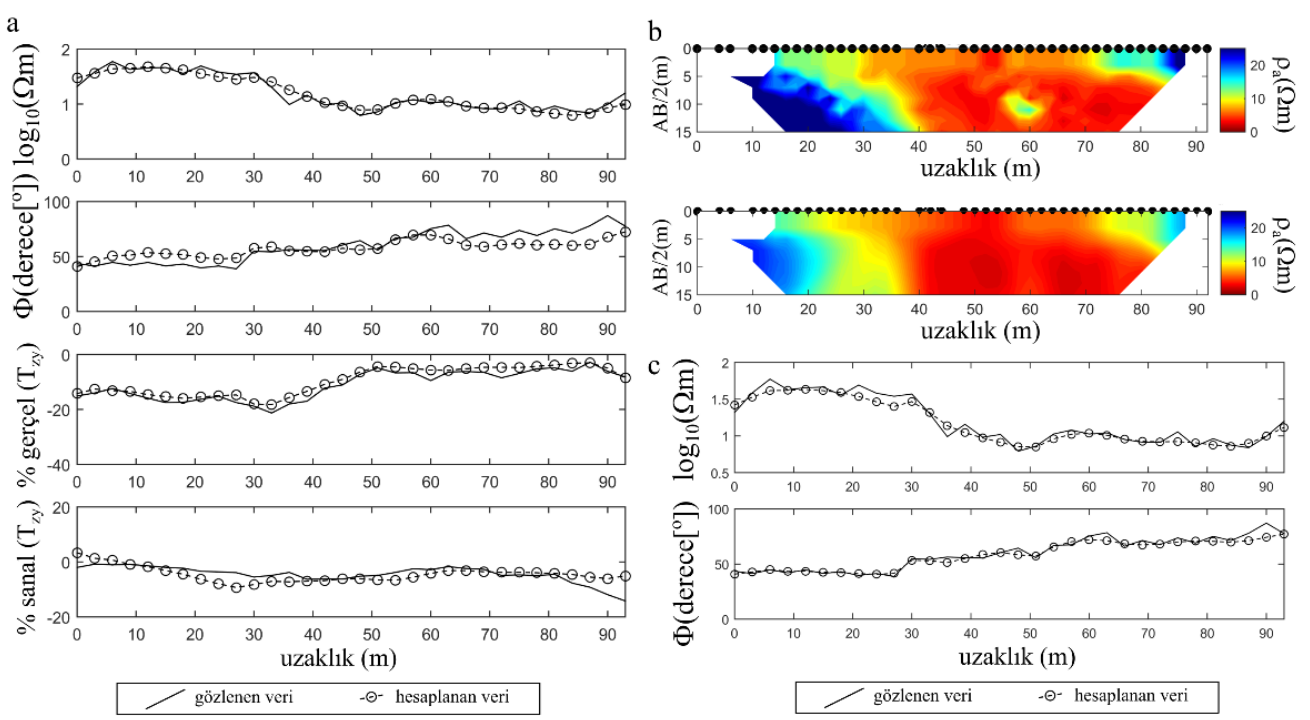

Şekil 8. a) Hat-1 üzerinde toplanmış az saçlım gösteren VLF-R verileri ve ters çözüm sonucuna ait hesaplanan veriler ( 9 yineleme, 1,23 RMS), b) Gözlenen ERT verileri (üstte) ve ters çözüm sonucuna (6 yineleme, 2,51 RMS) ait hesaplanan veriler (altta). c) VLF-R verilerinden sadece görünür özdirenç ve faz verilerinin ters çözümü sonucuna ait gözlenen ve hesaplanan veriler ( 5 yineleme, 1 RMS).
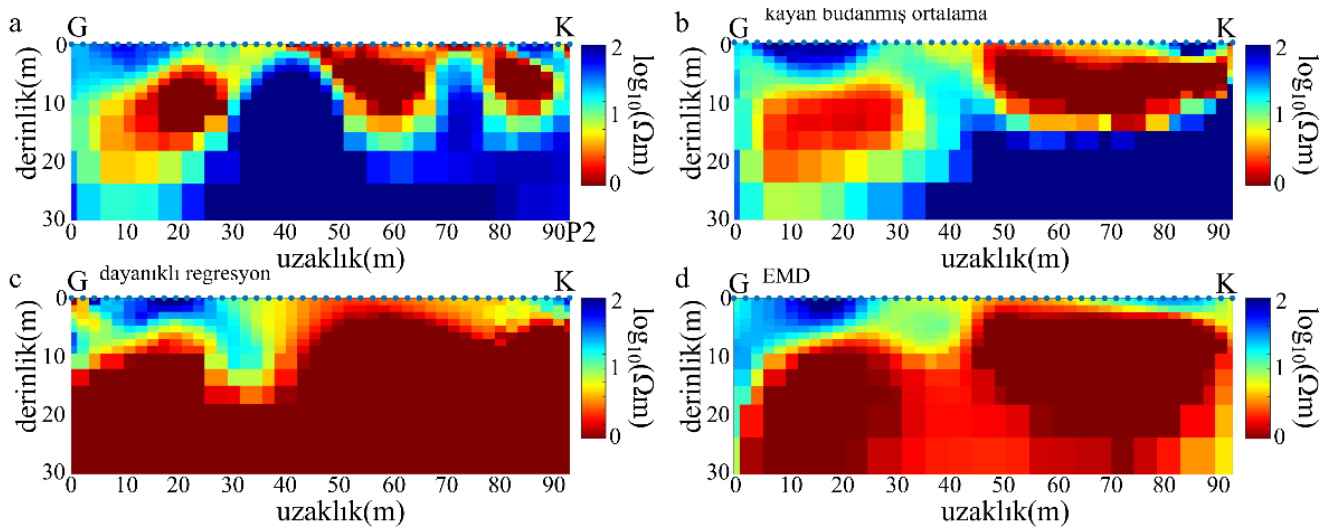

Şekil 9. Hat-2 üzerinde toplanan, yüksek saçlım gösteren VLF-R verileri için a) süzgeçlenmemiş verilerin yuvarlatıcılı ters çözüm sonucu (7 yineleme 2,6 RMS), b) budanmış ortalama (5 yineleme, 1 RMS), c) dayanıklı regresyon (3 yineleme, 1,1 RMS), d) EMD uygulanması sonucu elde edilen model (4 yineleme, 1,1 RMS).

Dayanıklı regresyon modelinde (3 yineleme, 1 RMS) ise fayın konumu Șekil 7a'ya oldukça benzer şekilde elde edilmiştir. Arazi verilerinden elde edilen sonuçlar da dayanıklı regresyonun daha başarılı olduğunu göstermektedir. Şekil 9'da verilen bu modellere ait gözlenen ve hesaplanan veriler Şekil 11'de sunulmuştur.

\section{Tartışma ve Sonuç}

VLF yönteminde veriler genelde periyodik olmayan veriler içerdiğinden gürültülerin giderilmesi için sıklıkla doğrusal olmayan süzgeçler uygulanmaktadır. Bunlardan VLF verilerinin işlenmesinde en çok kullanılanlarından biri de EMD yöntemidir. Kayan budanmış ortalama ve dayanıklı regresyon uygulamaları ise görece azdır. 
DEÜ FMD 24(70), 7-18, 2022

Aykırı değerler içeren kuramsal veriler ve Kocaeli' de KAF yüzey kırığı üzerinde toplanmıș arazi verileri üzerinde, süzgeçlenmiş ve süzgeçlenmemiş değerlerle gerçekleștirilen iki boyutlu yuvarlatıcılı ters çözüm sonuçları kıyaslanmıştır.

EMD süzgeci, verilerde gürültü olsa dahi aykırı değer bulunmadığını; varsa aykırı değerlerin birbirine yakın hatta ardașık noktalarda yeralması gerektiğini varsaymaktadır. Veriler bu koșulu sağlamıyorsa EMD süzgeci bașarısız olmaktadır. Gerçekleştirilen kuramsal ve arazi uygulamalarında, kulanıcı yorumuyla aykırı değerler süzgece tanımlanmaya çalıșılmasına rağmen istenen başarı sağlanamamıștır. Kayan budanmıș ortalama ise herhangi bir kullanıcı müdahelesine gerek duymadan EMD süzgeci ile karşılaştırılabilir modeller elde edilmesini sağlayabilmiştir, ancak bu yöntem de aykırı değerlerin etkisini verilerden yeterince giderememiștir. Dayanıklı regresyon ise hem kuramsal hem de arazi verilerinde belirti veren yapıların konumlarının belirlenebilmesini sağlamıştır. Elde edilen sonuçlar, verilerde aykırı
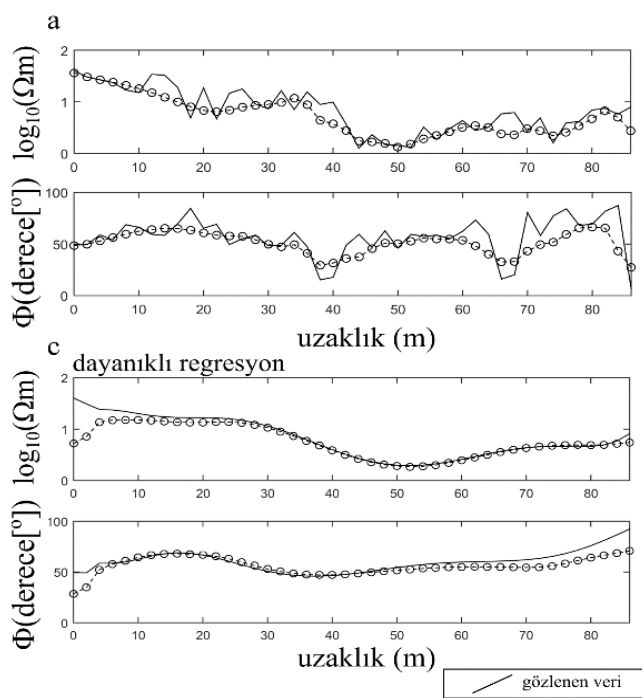

değerler olması durumunda, sınanan doğrusal olmayan süzgeçler içerisinde en başarılı olanın dayanıklı regresyon olduğunu ortaya koymustur.
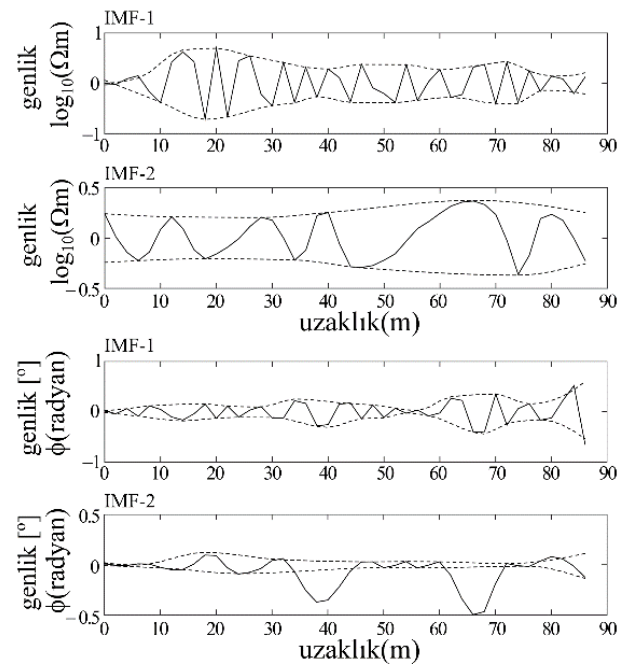

Şekil 10. Hat-2 için EMD uygulamasıyla verilerden atılan IMF'ler.

b kayan budanmış ortalama

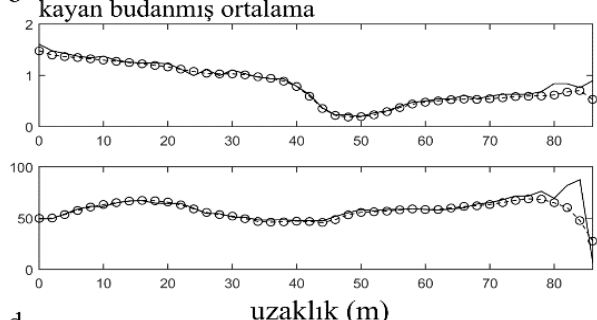
d EMD uzaklik (m)
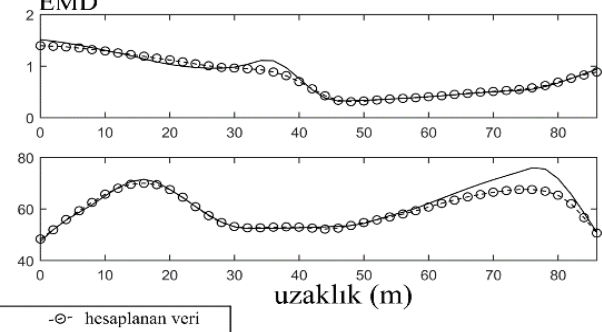

Şekil 11. Hat-2 üzerinde toplanan, yüksek saçılım gösteren VLF-R verileri için a) süzgeçlenmemiş verilerin yuvarlatıcılı ters çözüm sonucu (7 yineleme, 2,6 RMS), b) budanmış ortalama (5 yineleme, 1 RMS), c) dayanıklı regresyon (3 yineleme, 1,1 RMS), d) EMD uygulanması sonucu elde edilen modeller (4 yineleme, 1,1 RMS).

\section{Teşekkür}

Bu çalışma İstanbul Üniversitesi - Cerrahpaşa Bilimsel Araștırma Projeleri Koordinasyon Birimi tarafindan desteklenmiştir. Proje numarası: BYP-2019-34096.
Bu çalışmaya verdikleri katkılardan ötürü Prof.Dr. Ömer Feyzi Gürer'e ve Prof.Dr. Aysan Gürer'e teşekkür ederiz. Öneri ve eleștirileri ile bu çalıșmaya katkıda bulunan editör ve hakemlere teșekkür ederiz. 


\section{Kaynakça}

[1] Bayrak, M., Şenel, L., 2012. Two-dimensional resistivity imaging in the Kestelek boron area by VLF and DC resistivity methods. Journal of applied geophysics, Cilt. 82, 1-10. DOI: 10.1016/j.jappgeo.2012.03.010

[2] Gürer, A., Bayrak, M., Gürer, Ö. F., \& Şahin, S. Y., 2008. Deliniation of weathering in the Catalca granite quarry with the very low frequency (VLF) electromagnetic method. Pure and Applied Geophysics, Cilt. 165(2), 429-441. DOI: 10.1007/s00024-008-0304-1

[3] Drahor, M.G., Berge, M.A., 2006. Geophysical investigations of the Seferihisar geothermal area, Western Anatolia, Turkey, Geothermics, Cilt 35, 302 320. DOI: 10.1016/j.geothermics.2006.04.001

[4] Timur, E., 2014. Magnetic susceptibility and VLF-R investigations for determining geothermal blowout contaminated area: a case study from Alaşehir (Manisa/Turkey). Environmental earth sciences, Cilt. 72(7), 2497-2510. DOI: 10.1007/s12665-014 3158-0

[5] Olesen, O., Henkel, H., Lile, O.B., Mauring, E., Ronning J.S., 1992. Geophysical inverstigations of the Stuoragurra postglacial fault, Finnmark, northern Norway. Journal of Applied Geophysics., Cilt. 29, 95118. DOI: 10.1016/0926-9851(92)90001-2

[6] Yamaguchi, S., Murakami, S., Inokuchi, H., 2001 Resistivity mapping using the VLF-MT method around surface fault ruptures of the 1995 Hyogo-ken Nanbu earthquake, Japan. The Island Arc, Cilt. 10 296-305. DOI: 10.1111/j.1440-1738.2001.00328.x

[7] Gürer, A., Bayrak, M., Gürer, Ö.F., 2009. A VLF survey using current gathering phenomena for tracing buried faults of Fethiye-Burdur Fault Zone, Turkey. Journal of Applied Geophysics, Cilt. 68, 437-447. DOI: 10.1016/j.jappgeo.2009.03.011

[8] Beamish, D, Clasen, D, Greenwood, P. G, \& Peart, R J. , 1997. Novel regularized inversion of VLF (R) data and coincident radar sections over a probable fault affecting carboniferous sedimentary rocks in the Saar region, Germany. Geological Society, London, Engineering Geology Special Publications, Cilt. 12(1), 45-52. DOI: 10.1144/GSL.ENG.1997.012.01.03

[9] İlkişik, O. M., Bayrak, M., Başaran, S., Başokur, A. T., \& Elegergerli, E., 1995. Enez-Çataltepe Tümülüsünde Elektromanyetik-VLF ve Elektrik Araștırmalar Jeofizik Dergisi, Cilt. 9(1)

[10] Timur, E., 2012. VLF-R studies in the Agora of Magnesia archaeological site, Aydin, Turkey. Journa of Geophysics and Engineering, Cilt. 9(6), 697-710. DOI: $10.1088 / 1742-2132 / 9 / 6 / 697$

[11] Karlık, G., \& Kaya, M. A., 2001. Investigation of groundwater contamination using electric and electromagnetic methods at an open waste-disposa site: a case study from Isparta, Turkey. Environmental Geology, Cilt. 40(6), 725-731. DOI: 10.1007/s002540000232

[12] Kaya, M. A, Özürlan, G, \& Sengül, E, 2007. Delineation of soil and groundwater contamination using geophysical methods at a waste disposal site in Canakkale, Turkey. Environmental monitoring and assessment, Cilt. 135(1), 441-446. DOI: $10.1007 / \mathrm{s} 10661-007-9662-\mathrm{x}$
[13] Santos, F. M., Mateus, A., Figueiras, J., \& Gonçalves, M. A., 2006. Mapping groundwater contamination around a landfill facility using the VLF-EM methoda case study. Journal of Applied Geophysics, Cilt. 60(2), 115-125.

10.1016/j.jappgeo.2006.01.002

[14] Cagniard, L., 1953. Basic theory of the magnetotelluric method of geophysical prospecting. Geophysics, Cilt. 18(3), 605-635.

[15] Barr, R., Jones, D. L., \& Rodger, C. J., 2000. ELF and VLF radio waves. Journal of Atmospheric and SolarTerrestrial Physics, Cilt. 62(17-18), 1689-1718. DOI: 10.1016/S1364-6826(00)00121-8

[16] Chrissan, D. A., \& Fraser-Smith, A. C., 1996. Seasonal variations of globally measured ELF/VLF radio noise. Radio Science, Cilt. 31(5), 1141-1152.

[17] Henderson, T. R., Sonwalkar, V. S., Helliwell, R. A., Inan, U. S., \& Fraser-Smith, A. C., 1993. A search for ELF/VLF emissions induced by earthquakes as observed in the ionosphere by the DE 2 satellite. Journal of Geophysical Research: Space Physics, Cilt. 98(A6), 9503-9514. DOI: 10.1029/92JA01533

[18] Park, C. G., \& Helliwell, R. A., 1978. Magnetospheric effects of power line radiation. Science, Cilt. 200(4343), 727-730. DOI: $10.1126 /$ science.200.4343.727

[19] Everett, M. E., \& Weiss, C. J., 2002. Geological noise in near-surface electromagnetic induction data. Geophysical Research Letters, Cilt. 29(1), 10-1. DOI: 10.1029/2001GL014049

[20] Eppelbaum, L. V., \& Khesin, B. E., 1992. VLF method: elimination of noises and quantitative interpretation. In [Proceedings] 1992 Regional Symposium on Electromagnetic Compatibility (pp. 21). IEEE, November, 1992.

[21] Huang, N. E., Shen, Z., Long, S. R., Wu, M. C., Shih, H. H., Zheng, Q., Yen, N. C., Tung, C. C., Liu, H. H. , 1998. The empirical mode decomposition and the Hilbert spectrum for nonlinear and non-stationary time series analysis. Proceedings of the Royal Society of London. Series A: mathematical, physical and engineering sciences, 454(1971), 903-995. DOI: 10.1098/rspa.1998.0193

[22] Jeng, Y., Lin, M. J., Chen, C. S., \& Wang, Y. H., 2007. Noise reduction and data recovery for a VLF-EM survey using a nonlinear decomposition method. Geophysics, Cilt. 72(5), F223-F235. DOI: $10.1190 / 1.2752561$

[23] Verardi, V., \& Croux, C., 2009. Robust regression in Stata. The Stata Journal, Cilt. 9(3), 439-453. DOI: 10.1177/1536867X0900900306

[24] Bahri, A. S., Warnana, D. D., Santos, F. A. M., \& Santosa, B. J., 2014. Fast, simultaneous and robust VLF-EM data denoising and reconstruction via multivariate empirical mode decomposition. Computers \& Geosciences, Cilt. 67, 125-138, DOI: 10.1016/j.cageo.2014.03.007

[25] Bahri, A. S., \& Santosa, B. J., 2015. Application of Multivariate EMD to Improve Quality VLF-EM Data: Synthetic and Fields Data. Applied Mechanics and Materials, Cilt. 771, 170-173, Trans Tech Publications Ltd.

[26] Ebrahimi, A., Sundararajan, N., \& Babu, V. R., 2019. A comparative study for the source depth estimation of very low frequency electromagnetic (VLF-EM) 
signals. Journal of Applied Geophysics, Cilt. 162,174183. DOI: $10.1016 /$ j.jappgeo.2019.01.007

[27] Karcioğlu, G., 2019. Near-surface resistivity structure near avcilar landslide in Istanbul, Turkey by $2 \mathrm{D}$ inversion of VLF data. Journal of Applied Geophysics, Cilt. 163, 73-83. DOI: 10.1016/j.jappgeo.2019.02.012

[28] Kumar, S., Pal, S. K., \& Guha, A., 2020. Very low frequency electromagnetic (VLF-EM) study over Wajrakarur kimberlite Pipe 6 in Eastern Dharwar Craton, India. Journal of Earth System Science, Cilt. 129(1), 1-10. DOI: 10.1007/s12040-020-1367-3

[29] Sungkono, Santosa, B. J., Bahri, A. S., Santos, F. M., \& Iswahyudi, A., 2017. Application of Noise-Assisted Multivariate Empirical Mode Decomposition in VLFEM Data to Identify Underground River. Advances in Data Science and Adaptive Analysis, Cilt. 9(01), 1650011. DOI: $10.1142 / S 2424922 X 1650011 X$

[30] Candansayar, M. E., 2008. Two-dimensional inversion of magnetotelluric data with consecutive use of conjugate gradient and least-squares solution with singular value decomposition algorithms. Geophysical Prospecting, Cilt. 56(1), 141-157. DOI: 10.1111/j.1365-2478.2007.00668.x

[31] Özyıldırım, Ö., Candansayar, M. E., Demirci, İ., \& Tezkan, B., 2017. Two-dimensional inversion of magnetotelluric/radiomagnetotelluric data by using unstructured mesh. Geophysics, Cilt. 82(4), E197E210. DOI: 10.1190/geo2016-0378.1

[32] Özyıldırım, Ö., Demirci, İ., Gündoğdu, N. Y., \& Candansayar, M. E., 2020. Two dimensional joint inversion of direct current resistivity and radiomagnetotelluric data based on unstructured mesh. Journal of Applied Geophysics, Cilt. 172, 103885. DOI: 10.1016/j.jappgeo.2019.103885

[33] Triggs B., McLauchlan P.F., Hartley R.I., Fitzgibbon A.W., 2000. Bundle Adjustment - A Modern Synthesis. In: Triggs B., Zisserman A., Szeliski R. (eds) Vision Algorithms: Theory and Practice. IWVA 1999. Lecture Notes in Computer Science, vol 1883 Springer, Berlin, Heidelberg. DOI: 10.1007/3-54044480-7_21

[34] Stromberg, A., 2004. Why write statistical software? The case of robust statistical methods. Journal of Statistical Software, Cilt. 10(5), 1-8.

[35] Virtanen, P., Gommers, R., Oliphant, T. E., Haberland, M., Reddy, T., Cournapeau, D., Burovski, E., Peterson, P., Weckesser, W., Bright, J., van der Walt, S. J., Brett, M., Wilson, J., Jarrod Millman, K., Mayorov, N., Nelson, A. R. J., Jones, E., Kern, R., Larson, E., Carey, C., Polat, I., Feng, Y., Moore, E. W., VanderPlas, J., Laxalde, D, Perktold, J., Cimrman, R., Henriksen, I., Quintero, E. A. Harris, C. R., Archibald, A. M., Ribeiro, A. H., Pedregosa, F., van Mulbregt, P., and SciPy 1.0 Contributors, 2020. SciPy 1.0: Fundamental Algorithms for Scientific Computing in Python. Nat Methods, Cilt. 17, 261-272. DOI: 10.1038/s41592019-0686-2

[36] Constable, S. C., Parker, R. L., \& Constable, C. G., 1987. Occam's inversion: A practical algorithm for generating smooth models from electromagnetic sounding data. Geophysics, Cilt. 52(3), 289-300. DOI: $10.1190 / 1.1442303$

[37] de Groot-Hedlin, C., \& Constable, S., 1990. Occam's inversion to generate smooth, two-dimensional models from magnetotelluric data. Geophysics, Cilt. 55(12), 1613-1624. DOI: 10.1190/1.1442813

[38] Kurtuluș, C., Bozkurt, A., 2010. Bașiskele-Kocaeli Civarında Yer Altı Suyu Akiferlerinin Tespiti Jeofizik ve Sondaj Araștırmaları. Uygulamalı Yerbilimleri Dergisi, Cilt. 9(2), 1-9.

[39] Karakas, A., \& Coruk, O., 2010. Liquefaction analysis of soils in the western Izmit basin, Turkey. Environmental \& Engineering Geoscience, Cilt. 16(4), 411-430. DOI: 10.2113/gseegeosci.16.4.411

[40] Amatyakul, P., Vachiratienchai, C., \& Siripunvaraporn, W., 2017. WSJointInv2D-MT-DCR: An efficient joint two-dimensional magnetotelluric and direct current resistivity inversion. Computers \& Geosciences, Cilt. 102, 100-108. DOI: 10.1016/j.cageo.2017.02.010 